\title{
Basic and clinical immunology - 3016. Successful desensitization to oxaliplatin for metastic colorectal carcinoma
}

\author{
Praveen Buddiga*, Malik Baz \\ From 2nd WAO International Scientific Conference (WISC 2012) \\ Hyderabad, India. 6-9 December 2012
}

\section{Background}

Oxaliplatin is a platinum based agent that is a antineoplastic used in colorectal carcinoma in combination with flourouracil and leucovorin. A 45 year old female patient developed anaphylaxis on prior 2 cycles to this platinum agent with dyspnea and hypotension on the latter cycle. Further cycles were stopped and an allergist consult was obtained.

\section{Method}

In this case a premedication protocol of dexamethasone $10 \mathrm{mg}+$ diphenhydramine $50 \mathrm{mg}+$ famotidine $20 \mathrm{mg}$ by mouth were administered 13 hours, 6 hours and 1 hour respectively prior to the infusion of $40 \mathrm{mg}$ of oxaliplatin in 1:10000, 1:1000, 1:100, 1:10 graded dilutions. Each dilution was infused over 1 hour under close telemetry monitoring. A final dilution that contained $90 \%$ of the dose was infused over 4 hours until completion.

\section{Results}

The patient tolerated the desensitization protocol well with the premedication of dexamethasone+diphenhydramine+famotidine. The graded dilutional desensitization approach allowed the patient to achieve tolerance to the drug without any significant adverse events and was able to continue her cycles of antineoplastic regimen.

\section{Conclusions}

This graded desensitization protocol permits the continuation of antineoplastic treatment protocols in patients that may have a varying degrees of hypersensitivity to oxaliplatin agents.

\footnotetext{
University of California, San Francisco, Baz Allergy, Asthma \& Sinus Center,
} Fresno, CA, USA

(c) 2013 Buddiga and Baz; licensee BioMed Central Ltd. This is an Open Access article distributed under the terms of the Creative Commons Attribution License (http://creativecommons.org/licenses/by/2.0), which permits unrestricted use, distribution, and reproduction in any medium, provided the original work is properly cited.
A premedicated patient in addition to a graded drug dilution approach may allow administration of this potential life saving drug. The patient must at all times during the protocol be closely monitored for any treatment adjustments for tolerability.

Published: 23 April 2013

doi:10.1186/1939-4551-6-S1-P192 3016. Successful desensitization to oxaliplatin for metastic colorectal carcinoma. World Allergy Organization Journal 2013 6(Suppl 1):P192.
Cite this article as: Buddiga and Baz: Basic and clinical immunology -
Submit your next manuscript to BioMed Central and take full advantage of:

- Convenient online submission

- Thorough peer review

- No space constraints or color figure charges

- Immediate publication on acceptance

- Inclusion in PubMed, CAS, Scopus and Google Scholar

- Research which is freely available for redistribution 